\title{
INFLUÊNCIA DO AMBIENTE TROPICAL EM LODOS GERADOS NA ESTAÇÃO DE TRATAMENTO DE ESGOTOS DE BARUERI-SP: COMPORTAMENTO DOS METAIS PESADOS
}

\author{
JOSÉ CARLOS BRANCO DE ASSUNÇÃO* \& JOEL BARBUJIANI SÍGOLO**
}

\begin{abstract}
This study aims to characterize the geochemical behavior of $\mathrm{Ag}, \mathrm{Cd}, \mathrm{Cr}, \mathrm{Cu}, \mathrm{Fe}, \mathrm{Mn}, \mathrm{Ni}, \mathrm{Pb}$ and $\mathrm{Zn}$ incorporated into the sludges produced at Wastewater Treatment Plant (WTP) of Barueri, SP, contrasting the average metal content of the fresh sludges with metal content measured in the same sludges after their exposition to natural tropical climate conditions for about 15 months. The effects of sludges on the soil were also observed. The WTP of Barueri processes sewages from the São Paulo Metropolitan Region applying an activated sludge method followed by anaerobic digestion and chemical coagulation with precipitation by $\mathrm{Fel}_{3}$ and $\mathrm{Ca}(\mathrm{OH})_{2}$. Metal content and $\mathrm{pH}$ of the produced sludge ("fresh waste") are ordinarily measured by periodical monitoring at WTP. The fresh waste was cumulatively disposed directly over the soil in open air for about 15 months until forming a $2,20 \mathrm{~m}$ thick layer. During this study, this air-exposed waste ("disposed waste") and the undrlying soil were sampled for determination of $\mathrm{pH}$ and heavy metal ( $\mathrm{Ag}, \mathrm{Cd}, \mathrm{Cr}, \mathrm{Cu}, \mathrm{Fe}, \mathrm{Mn}, \mathrm{Ni}, \mathrm{Pb}$ and $\mathrm{Zn}$ ) content. Results of the analyses showed significant removal of the metais originarily incorporated into the sludge. A superficial $1,30 \mathrm{~m}$ thick layer soil retained small amount of dissolved metais. Anomalous values at deeper zones of the soil profile were obtained only for $\mathrm{Ag}$ and $\mathrm{Cu}$. The removal of heavy metais from sludges with no significant retention by the soil below suggests that heavy metais must have remained in solution. Therefore, heavy metais may reach both surface and groundwater, as well as the biota.
\end{abstract}

Key words: Heavy metais, sewage sludges, solid wates

RESUMO Este trabalho pretende caracterizar o comportamento geoquímico dos metais $\mathrm{Ag}, \mathrm{Cd}, \mathrm{Cr}, \mathrm{Cu}, \mathrm{Fe}$, $\mathrm{Mn}, \mathrm{Ni}, \mathrm{Pb}$ e $\mathrm{Zn}$ contidos em Iodos gerados na Estação de Tratamento de Esgotos (ETE) de Barueri, SP, através da comparação dos teores médios dos referidos metais nos Iodos logo após sua geração, com os respectivos teores dosados nos mesmos Iodos depois da sua exposição às condições climáticas tropicais por um período médio de 15 meses. Foi analisado também o efeito desses resíduos no solo subjacente. A ETE de Barueri trata esgotos da Região Metropolitana de São Paulo aplicando o método do lodo ativado acrescido de uma etapa de digestão anaeróbia e outra de condicionamento químico por adição de $\mathrm{FeCh}$ e $\mathrm{Ca}(\mathrm{OH}) 2$. O resíduo final resultante do processo, aqui denominado resíduo fresco, teve os seus teores médios de metais e valores médios de $\mathrm{pH}$ monitorados no momento em que foram gerados, sendo disposto em seguida ao ar livre, diretamente sobre o solo, constituindo um grande corpo tabular com espessura média de $2,20 \mathrm{~m}$. Nesse corpo foram coletadas amostras de canal e de trado, tanto dos resíduos quanto do solo a eles sotoposto. Nessas amostras foram determinados o $\mathrm{pH}$ e os teores de $\mathrm{Ag}, \mathrm{Cd}, \mathrm{Cr}, \mathrm{Cu}, \mathrm{Mn}, \mathrm{Fe}, \mathrm{Ni}, \mathrm{Pb}$ e $\mathrm{Zn}$. Os resultados dessas análises comprovaram que houve eliminação de uma parcela significativa dos metais originalmente contidos nos resíduos. A camada superficial de solo com 1,30m de espessura, abaixo dos resíduos, reteve uma pequena quantidade dos metais remobilizados. Teores anómalos em zonas mais profundas do perfil de solo foram identificadas apenas para $\mathrm{Ag}$ e Cu. A intensa remoção de metais dos resíduos sem uma correspondente retenção pêlos solos sotopostos leva à conclusão de que os metais devem ter permanecido em solução, podendo assim ter contaminado águas subterrâneas e superficiais, além da biota local.

Palavras chave: Metais pesados, Iodos de esgotos, resíduos sólidos

INTRODUÇÃO Os esgotos gerados nos meios urbanos caracterizam-se pela mistura de efluentes domésticos e industriais. Segundo Eckenfelder (1991), os esgotos contêm inúmeros compostos orgânicos dentre os quais destacam-se: ácidos voláteis (fórmico, acético, propiônico, butírico e valérico), ácidos solúveis não voláteis (glutárico, glicólico, láctico, cítrico, benzóico e feniláctico), ácidos graxos (palmítico, esteárico e oleico), pelo menos 20 tipos de proteínas e aminoácidos, além de carboidratos (glucose, sacarose, lactose, galactose e frutose). Os esgotos são portadores também de ânions inorgânicos, tais como: sulfates, cloretos, nitratos, fosfatos, fluoretos e cianetos, além de uma série de cátions, dentre os quais os referentes aos metais: $\mathrm{Ag}, \mathrm{Cd}, \mathrm{Cr}$, $\mathrm{Cu}, \mathrm{Fe}, \mathrm{Hg}, \mathrm{Mn}, \mathrm{Ni}, \mathrm{Pb}$ e $\mathrm{Zn}$.

De forma geral, as Estações de Tratamento de Esgotos (ETE's) recebem os esgotos in natura e os submetem a uma série de processos físicos, químicos e biológicos que têm por objetivo eliminar da água contaminada as diversas substâncias indesejáveis nela contidas, possibilitando assim o seu retorno ao meio ambiente com características sanitárias mais adequadas (Negulescu 1985). Deve-se ressaltar no entanto, que tais processos não destroem a totalidade das substâncias indesejáveis. Muitas delas são apenas removidas da água e concentradas em Iodos, que passam assim a constituir o resíduo final dos processos de tratamento. Esses Iodos carregam con- sigo significativa parcela do potencial poluidor dos esgotos dos quais se originaram e, portanto, apresentam teores variáveis de muitas substâncias prejudiciais ao meio ambiente. Dentre estas destacam-se os metais pesados.

Do ponto de vista químico, existem 38 elementos classificáveis como metais pesados (Cotrim 1991). Tais elementos são bons condutores de eletricidade, mostram relação inversa entre sua condutividade elétrica e a temperatura absoluta, relação direta entre sua resistividade elétrica e a temperatura absoluta e, além disso, apresentam peso específico maior ou igual a $5,0 \mathrm{~g} / \mathrm{cm}^{3}$ (Förstner \& Wittmann 1981). Já do ponto de vista ambiental, a denominação "metais pesados" costuma ser empregada para identificar um conjunto de elementos que podem causar impactos negativos ao meio ambiente.

Tal conjunto é, na realidade, constituído por metais e metalóides, principalmente por : Ag, $\mathrm{As}, \mathrm{B}, \mathrm{Ba}, \mathrm{Co}, \mathrm{Cd}, \mathrm{Cr}$, $\mathrm{Cu}, \mathrm{Fe}, \mathrm{Hg}, \mathrm{Mn}, \mathrm{Mo}, \mathrm{Ni}, \mathrm{Pb}, \mathrm{Se}$, Sn e $\mathrm{Zn}$. Em Iodos residuais de ETE' s é comum a presença de vários desses elementos, que têm algumas de suas principais características apresentadas na Tabela 1.

Os prejuízos que podem resultar da disseminação descontrolada de metais pesados no meio ambiente, amplamente relatados na literatura, exigem que os Iodos residuais de ETE's tenham uma disposição final muito criteriosa. Infelizmente, a grande variabilidade da sua composição química

* Aluno de pós-graduação do DGG do Instituto de Geociências da USP

** Instituto de Geociências da Universidade de São Paulo, Caixa Postal 11348, CEP 05422-970 - São Paulo - SP 
e a elevada magnitude dos volumes gerados têm dificultado essa tarefa.

Buscando soluções para este problema, diversos pesquisadores vêm estudando o emprego na agricultura de Iodos com teores de metais situados dentro de certos limites, podendo ser citados como exemplo os trabalhos de Anderson \& Nilson (1972), Page(1974),Bigham et al. (1975), Jorgensen (1975), John \& Van Laerhoven (1976), Kelling et al. (1977), Strett et al. (1978), Lake et al. (1984) e Smith (1994). Enquanto isto, outros pesquisadores têm estudado destinações alternativas para os Iodos, tais como incineração, lançamento ao oceano e utilização na fabricação de elementos para construção civil. Porém, ainda não se chegou ao consenso quanto à viabilidade ambiental e econômica dessas disposições alternativas.

Na prática, a solução mais adotada tem sido a colocação dos Iodos de ETE's em aterros especialmente construídos, que tentam evitar a migração dos elementos contaminantes para o meio circundante. E importante ressaltar que na grande maioria dos estudos realizados envolvendo essa solução, o solo, matéria prima dos aterros, foi encarado principalmente como uma barreira mecânica aos resíduos e, dessa forma, priorizou-se a avaliação das suas características geotécnicas, prioritariamente daquelas ligadas à sua permeabilidade.

Alguns pesquisadores entretanto, consideram o solo como elemento ativo no sistema, desempenhando um papel de agente atenuador e fixador dos elementos nocivos e, dessa forma, dão relevância também ao estudo das suas características geoquímicas (Garrigan 1977, Andersson 1977b e 1979, Alesii et al. 1980,Mattheus 1982,Schalscha et al. 1980 e 1982 e Fuller \&Warrick 1985).

É importante ressaltar, que praticamente todos esses trabalhos investigaram o comportamento de resíduos gerados com a utilização de técnicas de tratamento específicas, aplicadas a esgotos produzidos em países do primeiro mundo, com características sócio-econômicas particulares, situados em regiões que possuem solos e climas diferentes dos brasileiros e, por tudo isso, podem ter chegado a resultados distintos daqueles que seriam obtidos em pesquisas similares realizadas no Brasil. Por isso, as conclusões obtidas nesses trabalhos, sobre o comportamento dos Iodos e suas interações com os solos, podem não ser integralmente aplicáveis a problemas similares que ocorram em países tropicais.

No Brasil, alguns pesquisadores vêm estudando os processos de geração de Iodos, assim como o seu uso na agricultura (Bettiol 1982, Povinelli 1987, Cotrim 1991 e Damasceno 1996). Mesmo assim, até 1996, havia poucas pesquisas no
Brasil que estudassem, do ponto de vista da geoquímica, os fenómenos envolvidos na exposição de Iodos às condições climáticas tropicais, principalmente no que se refere ao comportamento dos metais pesados e às suas interações com solos naturais brasileiros. Essa linha de pesquisa foi abordada em 1996 num primeiro estudo sobre o comportamento geoquímico dos resíduos da ETE de Barueri (Assunção 1996).

A partir desse trabalho, novas pesquisas estão sendo feitas, tanto sobre a mobilidade dos metais nos Iodos como sobre a sua interação com os constituintes dos solos. Busca-se estabelecer o seu potencial de contaminação e as características dos solos mais sujeitas à sua influência.

O presente trabalho é mais uma contribuição nesse sentido. Ele busca determinar a mobilidade de metais pesados contidos em Iodos residuais da ETE de Barueri, que ficaram dispostos ao ar livre por aproximadamente 15 meses, sob influência de condições climáticas tropicais naturais.

A SITUAÇÃO ESTUDADA A Estação de Tratamento de Esgotos de Barueri, da Companhia de Saneamento Básico do Estado de São Paulo (Sabesp), funciona desde 1988, tratando uma parcela dos esgotos gerados na Região Metropolitana de São Paulo. A ETE de Barueri atende a uma população de 2,5 milhões de habitantes, processando uma vazão de $4,5 \mathrm{~m} / \mathrm{s}$ de esgotos que, de acordo com o Plano Diretor de Esgotos da Região Metropolitana de São Paulo, deverá atingir 28,5m /s até o ano de 2005 (Etep 1992).

As técnicas de tratamento utilizadas em Barueri resultam em média na geração diária de $127 \mathrm{~m}$ de Iodos residuais (São Paulo (Estado) 1994), que devem ser removidos dos equipamentos e instalações onde são produzidos. A contínua geração de resíduos aliada à necessidade da sua imediata remoção criam um problema, cuja solução tem se mostrado bastante complexa: determinar um local adequado para receber de forma definitiva os resíduos gerados. Desde o início da operação da ETE em 1988, fatores de ordem técnica e econômica impossibilitaram a definição desse local, e assim, a disposição dos resíduos a céu aberto, em áreas livres do terreno da própria estação, foi adotada em caráter provisório e precário até que se dispusesse de local ambientalmente adequado para recebê-los em caráter definitivo.

Por causa disto, praticamente todo o lodo produzido pela ETE desde 1988 permaneceu acumulado no terreno da estação, reşultando em 1994 num volume aproximado de $215.000 \mathrm{~m}^{3}$ de resíduos dispostos ao ar livre, em pilhas e camadas colocadas diretamente sobre o solo. Esses resíduos

Tabela l-Algumas características de metais normalmente presentes em Iodos de ETE'S

Table l-Some of ihe characteristics of metais normaly found in muds waste treatment stations

\begin{tabular}{|c|c|c|c|c|c|c|c|}
\hline CARACTERÍSTICA & Cd & $\mathrm{Cr}$ & $\mathrm{Cu}$ & Mn & $\mathrm{Ni}$ & $\mathrm{Pb}$ & Zn \\
\hline $\begin{array}{l}\text { Teor médio na crosta } \\
\text { terrestre }(\mathrm{mg} / \mathrm{kg})\end{array}$ & $\overline{0,2}$ & 100 & 55 & 1000 & 75 & 13 & 70 \\
\hline $\begin{array}{l}\text { Teor em seres vivos - De } \\
\text { plancton a mamfferos }(\mathrm{mg} / \mathrm{kg})\end{array}$ & 0,15 a 4,0 & 0,8 a 3,5 & 2.4 a 200 & $0,1 \mathrm{a} 250$ & 0,4 a 36 & 0,3 a 50 & 6 a 2600 \\
\hline $\begin{array}{l}\text { Teor nos mamíferos - tecidos } \\
\text { desidratados }(\mathrm{mg} / \mathrm{kg})\end{array}$ & 0,05 a 130 & 0,03 a 2,0 & $22 \times 196$ & $\begin{array}{c}0,21 \mathrm{a} \\
3,8\end{array}$ & 0,01 a 6 & $0, \overline{2}$ a 35 & 13 a 210 \\
\hline $\begin{array}{l}\text { Teor normal na dieta diária do } \\
\text { homem }(\mathrm{mg} / \mathrm{kg})\end{array}$ & 0,6 & 0,05 & $2 a 5$ & 3 a 9 & 0,3 a 0,5 & 0,3 a 0,4 & 10 a 15 \\
\hline $\begin{array}{l}\text { Teor tóxico na dieta diária do } \\
\text { homem }(\mathrm{mg} / \mathrm{kg})\end{array}$ & 3 & 200 & 250 a 500 & nd & nd & nd & nd \\
\hline $\begin{array}{l}\text { Estado mais comum em águas } \\
\text { naturais }\end{array}$ & $\mathrm{Cd}^{2+}$ & $\mathrm{Cr}^{3+}$ & $\begin{array}{c}\mathrm{Cu}^{2+} \mathrm{e} \\
\text { complexos }\end{array}$ & $\mathrm{Mn}^{2+}$ & $\mathrm{Ni}^{2+}$ & $\begin{array}{c}\mathrm{Pb}^{2+} \mathrm{e} \\
\mathrm{Pb}(\mathrm{OH})^{+}\end{array}$ & $\mathrm{Zn}^{2+}$ \\
\hline $\begin{array}{l}\text { Principais fontes de poluição } \\
\text { dos solos }\end{array}$ & $\begin{array}{c}\text { Mineração e } \\
\text { Lodos de } \\
\text { ETE's }\end{array}$ & $\begin{array}{c}\text { Agricultura. } \\
\text { Metalurgja e } \\
\text { Lodos de } \\
\text { ETE's }\end{array}$ & $\begin{array}{l}\text { Agricultura, } \\
\text { Indústria e } \\
\text { Lodos de } \\
\text { ETE's }\end{array}$ & Indústria & $\begin{array}{l}\text { Agricultura, } \\
\text { Indústria e } \\
\text { Lodos de } \\
\text { ETE's }\end{array}$ & $\begin{array}{c}\text { Mineração, } \\
\text { Indústria e } \\
\text { Lodos de } \\
\text { ETE's }\end{array}$ & $\begin{array}{l}\text { Agricultura e } \\
\text { Lodos de } \\
\text { ETE's }\end{array}$ \\
\hline
\end{tabular}

Condensado de: Jorgensen \& Johsen (1989), Alloway (1990), Damasceno (1996). 
acabaram por constituir quatro corpos independentes, que ocupam uma área total de cerca de $76.000 \mathrm{~m}$.

O lodo condicionado desidratado, aqui denominado "resíduo fresco", foi sendo depositado no terreno da ETE à medida em que foi sendo gerado. Como geração e disposição ocorreram de forma praticamente ininterrupta entre os anos de 1988e 1994, coexistiam no local no momento da realização dos trabalhos de campo desta pesquisa, resíduos gerados e dispostos em épocas diferentes e submetidos às condições ambientais por diferentes períodos de tempo. Assim, foi indispensável em primeiro lugar, determinar a cronologia da disposição dos Iodos na área da ETE.

CRONOLOGIA DA DISPOSIÇÃO DO LODO A disposição do lodo desidratado sobre o terreno da ETE originou quatro corpos, aqui denominados Norte, Sul, Leste e Oeste. A cronologia da disposição de cada um desses corpos foi levantada através de entrevistas realizadas com técnicos da Sabesp, que participaram diretamente dos trabalhos de disposição dos resíduos nos diversos locais.

A Tabela 2 apresenta os resultados desse levantamento, mostrando as principais características de cada um dos corpos de resíduo, no que diz respeito às suas dimensões, idades, tempos de exposição ao clima e tempo de contato com os solos subjacentes. Uma análise cuidadosa das características de cada um dos corpos levou à conclusão de que o corpo Norte seria o mais adequado para a realização deste primeiro estudo, pois ele apresentava diversas características favoráveis:

Boa margem de segurança na determinação das datas de geração e disposição dos resíduos frescos no terreno,

. Número adequado de amostras coletadas e analisadas pela

Sabesp para o monitoramento dos teores de metais dos resíduos frescos que vieram a originar o corpo (11 amostras),

. Pequena movimentação depois da disposição inicial,

Espessura satisfatória (média $=2,20 \mathrm{~m}$ ),

. Boas condições de acesso para amostragem,

Pequena declividade do terreno no local (1\%),

Tempo de disposição satisfatório (12 a 18 meses).

Portanto, o corpo Norte foi escolhido para ser caracterizado no presente trabalho.

\section{MATERIAIS E MÉTODOS Caracterização dos resíduos frescos que originaram o Corpo Norte}

A primeira etapa do trabalho consistiu no levantamento de características físico-químicas dos resíduos frescos gerados pela ETE, referentes a um instante imediatamente anterior à sua disposição ao ar livre.
Essa foi uma tarefa bastante simples, pois a Sabesp mantinha em arquivo os resultados do monitoramento periódico de vários parâmetros, relativos a efluentes e produtos gerados em cada uma das etapas do tratamento. Um desses produtos é o lodo condicionado desidratado, resíduo final do processo, e que foi disposto no terreno da ETE. Nesse monitoramento foram efetuadas coletas mensais de amostras do lodo, diretamente na esteira de saída do filtro prensa. As amostras coletadas foram analisadas pelo laboratório de análises químicas da ETE, sendo determinados os parâmetros: DBO, DQO, teor de resíduos sólidos, teor de umidade e teores de $\mathrm{Ag}, \mathrm{Cd}$, $\mathrm{Cr}, \mathrm{Cu}, \mathrm{Fe}, \mathrm{Hg}, \mathrm{Mn}, \mathrm{Ni}, \mathrm{Pb}$ e $\mathrm{Zn}$.

O monitoramento dos teores dos metais foi descontínuo entre 1988 e 1994, não havendo dados disponíveis para os anos de 1988 a 1990. Os dados referentes às amostras coletadas entre maio de 1991 e junho de 1994 sofreram uma avaliação da sua representatividade estatística, e dessa avaliação, concluiu-se que o conjunto de 11 análises referentes aos resíduos gerados entre março e setembro de 1993, que foram dispostos no Corpo Norte, poderiam ser utilizados no trabalho. Essas 11 determinações de teores de metais foram executadas com utilização do método de Espectrofotometria de Absorção Atômica em amostras previamente digeridas por ácidos fortes a quente $\left(\mathrm{HNO}_{3}+\mathrm{HC} 1\right)$.

Já as características do $\mathrm{pH}$ do resíduo fresco utilizadas neste trabalho, foram obtidas em relatório de caracterização dos Iodos condicionados desidratados, feito pela empresa Etatec Consultores S/C Ltda. para a Sabesp. Cerca de 8 amostras de lodo condicionado desidratado foram coletadas na esteira do filtro prensa, nos meses de março e abril de 1993, e submetidas à determinação do seu $\mathrm{pH}$, diretamente em suspensões do lodo em água deionizada.

Cabe salientar que a existência desses dados nos arquivos da Sabesp foi fundamental para a realização deste trabalho. Eles tornaram possível a definição das características médias iniciais dos resíduos frescos que estavam sendo dispostos no corpo Norte, no instante " $\mathrm{t}_{0}$ ", referente à sua geração e disposição no campo. Essa composição pôde então ser comparada com uma segunda composição, obtida depois da determinação dos mesmos parâmetros nos mesmos resíduos, somente que num instante " $\mathrm{t}_{\mathrm{n}}$ ", situado 15 meses depois deles terem sido dispostos ao ar livre e submetidos às condições climáticas tropicais naturais. As características relativas a esse segundo instante " $t_{n}$ ", foram obtidas por meio da coleta e análise de amostras dos resíduos dispostos no corpo Norte.

\section{Caracterização do resíduo disposto no corpo} Norte AMOSTRAGEM Procurou-se amostrar vertical-

Tabela 2 - Características dos corpos de resíduos dispostos em Barueri

Table 2 - Characteristics of waste bodies of Barueri

\begin{tabular}{|c|c|c|c|c|}
\hline \multirow[b]{2}{*}{ CARACTERÍSTICA } & \multicolumn{4}{|c|}{ CORPOS DE RESÍDUOS DISPOSTOS } \\
\hline & NORTE & SUL & LESTE & OESTE \\
\hline ÁREA OCUPADA $\left(\mathrm{m}^{2}\right)$ & 16.500 & 11.200 & 16.800 & 31.500 \\
\hline $\operatorname{VOLUME}\left(\mathrm{m}^{3}\right)$ & 36.300 & 31.700 & 42.400 & 112.300 \\
\hline PESO ESTIMADO (ton) & 54.500 & 47.600 & 63.600 & 168.500 \\
\hline ESPESSURA MÉDLA (m) & 2,20 & 2,83 & 2,53 & 3,57 \\
\hline $\begin{array}{l}\text { DATA DA GERAÇAO DO } \\
\text { RESÍDUO DISPOSTO } \\
\text { ATÉ JUNHO DE } 1994\end{array}$ & $\begin{array}{l}\text { a-jul } / 90 \text { a dez/90 } \\
\text { b-nov/92 e dez/92 } \\
\text { c-jan/93 a jul } / 93\end{array}$ & $\begin{array}{l}\text { a- jul/91 a fev/92 } \\
b-a b r / 94 \text { a jun/94 }\end{array}$ & $\begin{array}{l}\text { a-ago/93 a dez } / 93 \\
\text { b-jan/94 a mar/94 }\end{array}$ & $\begin{array}{c}\text { a-jul/88 a jun/90 } \\
\text { (vejo da área leste) } \\
\text { b-jan/9l a jun/9l }\end{array}$ \\
\hline Amostragem feita em & $\begin{array}{l}\text { jul/94 (amostrado } \\
\text { o resíduo tipo "c") }\end{array}$ & $\begin{array}{l}\text { Não amostrado para o } \\
\text { presente trabalho }\end{array}$ & $\begin{array}{l}\text { Não amostrado para o } \\
\text { presente trabalho }\end{array}$ & $\begin{array}{l}\text { Não amostrado para o } \\
\text { presente trabalho }\end{array}$ \\
\hline $\begin{array}{l}\text { Tempo médio de exposição } \\
\text { do resíduo amostrado }\end{array}$ & 15 meses & idem & idem & idem \\
\hline $\begin{array}{l}\text { Tempo de exposição do solo } \\
\text { amostrado sob o resíduo }\end{array}$ & 18 meses & idem & idem & idem \\
\hline
\end{tabular}


mente o corpo Norte e o solo situado abaixo dele, executandose um único perfil contendo resíduos e solos. Com esse objetivo, utilizou-se uma retro-escavadeira Poclain para cavar uma trincheira através do corpo de resíduos e do solo sotoposto no local escolhido, originando um afloramento recente, que pode ser amostrado depois da estabilização mecânica de suas paredes. Nessas paredes foram coletadas amostras de canal dos resíduos e do solo recém-exposto. Na base do afloramento, foram coletadas amostras do subsolo não exposto, com execução de amostragem a trado.

A amostragem de canal não exigiu equipamentos sofisticados, sendo utilizados apenas enxadão e espátula. A amostragem do subsolo foi feita com um trado tipo concha, com = 2,5", dotado de hastes de engate rápido. Foram executados os seguintes procedimentos:

Amostras de canal: Coletadas 6 amostras de resíduos em $2,80 \mathrm{~m}$ de parede e 7 amostras do solo sotoposto em $1,70 \mathrm{~m}$ da mesma parede; resultando um total de 13 amostras em um perfil com 4,50m de altura.

Amostras de trado: Coletadas 8 amostras do solo sotoposto, num furo com $1,60 \mathrm{~m}$ de profundidade, aberto na base do perfil anteriormente descrito.

Foram coletadas portanto 21 amostras de canal e de trado para a execução das análises. Depois da coleta as amostras foram submetidas a uma série de procedimentos, que serão descritos a seguir.

TRABALHOS DE LABORATÓRIO Preparação das amostras As amostras passaram por uma preparação inicial no laboratório de preparação de amostras do DGG - IGUSP, que consistiu em:

Secagem inicial - As amostras foram secas à temperatura ambiente, expostas durante o período médio de uma semana em bandejas de madeira recobertas por papel, até que fosse possível a sua desagregação manual.

Homogeneização, quarteamento e peneiramento - As amostras foram homogeneizadas e quarteadas com a utilização da técnica da pilha cônica (Possa \& Luz 1984). As amostras enviadas para dosagem de metais pesados foram moídas manualmente, abaixo de 150 mesh, em grau de ágata.

Análises químicas - Submeteu-se as amostras a duas análises:

. Determinação do $\mathrm{pH}$ - Nas alíquotas de amostras previamente secas determinou-se o $\mathrm{pH}$ de abrasão em equipamento Expandable Ion Analiser modelo E-A 920. Adicionou-se 10g de amostra a $30 \mathrm{ml}$ de água deionizada e a mistura foi agitada mecanicamente por 5 minutos, ficando a seguir em repouso por cerca de 1 hora. Transcorrido esse período, efetuou-se a leitura do valor do $\mathrm{pH}$.

Dosagem de metais pesados - As alíquotas de resíduos e solos foram submetidas à dosagem dos metais $\mathrm{Ag}, \mathrm{Cd}, \mathrm{Cr}$, $\mathrm{Cu}, \mathrm{Fe}, \mathrm{Mn}, \mathrm{Ni}, \mathrm{Pb}$ e $\mathrm{Zn}$. Essa determinação foi feita a partir de abertura por ácidos fortes a quente, feita com a utilização de $\mathrm{HNO}_{3}$ e $\mathrm{HCl}$, adicionados na proporção de $1: 3$ e aquecidos sob refluxo a uma temperatura de $100^{\circ} \mathrm{C}$, até a dissolução das amostras.

As soluções foram analisadas por Espectro fotometria de Absorção Atômica, em espectrofotômetro Varian modelo AA-1475. Dosou-se paralelamente amostras padrão e brancos para verificação e controle da qualidade dos resultados.

É importante salientar que foram empregados nos resíduos dispostos os mesmos métodos que já haviam sido aplicados pela Sabesp no monitoramento dos resíduos frescos.

\section{RESULTADOS OBTIDOS Caracterização do resíduo fresco DETERMINAÇÃO DO $\mathrm{pH} M E D D I O$}

Os valores de $\mathrm{pH}$ 's monitorados em amostras dos resíduos frescos que originaram o corpo Norte são apresentados na Tabela 3. De acordo com essa tabela, esses lodos frescos apresentavam $\mathrm{pH}$ médio de 11,55 . O pH mínimo medido foi de 10,00 e o máximo de 12,42. Esses resultados são muito semelhantes aos apresentados por Eckenfelder 1991, que afirma que os procedimentos envolvidos na geração de Iodos condicionados geram pH's bastante elevados, propiciando ambientes francamente alcalinos. Esses resíduos, com pH's médios superiores a 11 , foram dispostos ao ar livre no terreno da ETE e vieram a constituir o corpo Norte.

DETERMINAÇÃO DOS TEORES MÉDIOS DE METAIS PE$S A D O S \mathrm{O}$ presente trabalho exigiu a definição de valores médios confiáveis para os teores dos resíduos frescos. Exigiu também que cada valor médio pudesse ser corretamente associado a resíduos gerados em datas determináveis e dispostos em locais também determináveis. Com esse objetivo, todos os resultados levantados nos arquivos da Sabesp foram submetidos a tratamento estatístico clássico, tarefa que resultou em valores médios anuais para os teores de cada metal. A esses valores médios anuais foi acrescentado um erro da média, corrigido pelo fator " $t$ " de Student, calculado para um limite de confiança de $90 \%$. Esse procedimento resultou nos valores apresentados na Tabela 4.

O levantamento da cronologia de disposição dos resíduos no campo, exibido na Tabela 2 , já havia mostrado que o corpo mais adequado para a presente caracterização seria o corpo Norte e que os resíduos frescos depositados no corpo Norte foram gerados no primeiro semestre de 1993. Dessa forma, os teores médios iniciais de cada metal nos resíduos frescos dispostos no corpo Norte, referentes portanto ao seu instante " $\mathrm{t}_{0}$ ", são os teores médios mostrados na linha hachurada da Tabela 4. Portanto, esses são os teores utilizados neste trabalho.

Caracterização do resíduo disposto DETERMI$N A C ̧ \tilde{A} O D O \mathrm{pH}$ - Os resultados das determinações de $\mathrm{pH}$ nos resíduos dispostos são mostrados na Tabela 5. Verifica-se que os resíduos dispostos apresentam $\mathrm{pH}$ médio situado entre 7,37 e 7,65 , caracterizando condições próximas à neutralidade. Como os resíduos frescos originais apresentavam quando gerados valores de pH's situados entre 10,00 e 12,42, fica evidente a ocorrência de uma diminuição nos seus valores. Esse fenômeno pode estar relacionado à exposição dos resíduos às condições ambientais tropicais.

A diminuição no valor do $\mathrm{pH}$ pode ter contribuído para um aumento da solubilidade, e consequentemente da mobilidade, da maioria dos metais pesados contidos nos resíduos, como demonstram diversos trabalhos sobre a influência do $\mathrm{pH}$ na solubilidade de metais, tanto em Iodos de ETE's quanto em solos naturais (Argaman \& Weddle 1973, Jorgensen 1975, Andersson 1977a, Calmano 1988 e Gemert et al. 1988).

Além da comparação do $\mathrm{pH}$ dos resíduos dispostos com os dos resíduos frescos originais, pode-se observar também a variação dos valores de $\mathrm{pH}$ dentro do próprio corpo de resíduo, como mostra a Figura 1. Nota-se uma discreta tendência de diminuição do $\mathrm{pH}$ em direção ao topo do pacote. Esse comportamento sugere que a causa da diminuição do $\mathrm{pH}$ pode estar relacionada a fenômenos originados no meio externo. Nesse sentido, Campanella et al. (1986) afirmam que os metais contidos em Iodos de ETE's podem ser solubilizados em condições naturais se submetidos a chuvas ácidas. O presente trabalho não pesquisou as características físico-químicas das chuvas em Barueri, não verificando essa hipótese.

DETERMINAÇÃO DOS TEORES DE METAIS PESADOS Os resultados da determinação dos teores dos metais pesados nos resíduos são mostrados na Tabela 6 . Os teores obtidos foram comparados com os respectivos teores nos resíduos frescos originais e também entre si, no próprio corpo de resíduos. Os resultados são discutidos a seguir. 
Tabela 3 - Valores de pH medidos diretamente no resíduo fresco disposto no Corpo Norte

Table 3 - Values of pH measured directly in the fresh residue of the North Body of the Barueri Waste Disposal Plant.

\begin{tabular}{|c|c|c|c|}
\hline AMOSTRA & $\mathrm{pH}$ & AMOSTRA & $\mathrm{pH}$ \\
\hline TCA-683 & 11,96 & TCA-684 & 11,55 \\
TCA-954 & 12,42 & TCA-955 & 11,80 \\
TCA-1019 & 11,96 & TCA-1020 & 11,00 \\
TCA-1064 & 10,00 & TCA-1065 & 11,70 \\
\hline VALOR MÍNIMO: & 10,00 & VALOR MÉDIO: & 11,55 \\
VALOR MÁXIMO: & 12,42 & & \\
\hline
\end{tabular}

Fonte: Etatec (1993).

Tabela 4 - Teores médios anuais calculados dos metais contidos nos resíduos frescos

Table 4 - Calculated mean annual contents of metais in fresh residues

\begin{tabular}{|c|c|c|c|c|c|c|c|}
\hline \multirow{2}{*}{ ANO } & \multicolumn{6}{|c|}{ TEORES MÉDIOS NOS RESIDUOS FRESCOS (mg/kg-base seca) (Limite de confiança de 90\%) } \\
\cline { 2 - 8 } & $\mathrm{Ag}$ & $\mathrm{Cd}$ & $\mathrm{Cr}$ & $\mathrm{Cu}$ & $\mathrm{Ni}$ & $\mathrm{Pb}$ & $\mathrm{Zn}$ \\
\hline 1991 & $63,20 \pm$ & $20,67 \pm$ & $1898,17 \pm$ & $1488,50 \pm$ & $749,83 \pm$ & $506,67 \pm$ & $4042,50 \pm$ \\
& 32,98 & 7,29 & 403,10 & 601,46 & 347,39 & 199,38 & 872,80 \\
\hline 1992 & $83,00 \pm$ & $97,00 \pm$ & $1789,40 \pm$ & $2515,80 \pm$ & $2148,20 \pm$ & $576,00 \pm$ & $4384,00 \pm$ \\
& 386,44 & 0 & 270,19 & 946,03 & 634,78 & 204,04 & 615,49 \\
\hline $\mathbf{1 9 9 3}$ & $\mathbf{5 0 , 0 0 \pm}$ & $\mathbf{2 5 , 6 7} \pm$ & $\mathbf{8 0 5 , 4 5} \pm$ & $\mathbf{7 3 8 , 8 2} \pm$ & $\mathbf{4 7 8 , 0 0} \pm$ & $\mathbf{3 0 2 , 4 4} \pm$ & $\mathbf{1 4 7 4 , 9 0} \pm$ \\
& $\mathbf{1 6 , 1 1}$ & $\mathbf{3 , 1 9}$ & $\mathbf{1 9 5 , 4 4}$ & $\mathbf{2 1 6 , 7 7}$ & $\mathbf{1 1 1 , 0 4}$ & $\mathbf{1 0 3 , 0 8}$ & $\mathbf{2 8 2 , 2 9}$ \\
\hline 1994 & $108,47 \pm$ & $21,67 \pm$ & $916,80 \pm$ & $869,93 \pm$ & $492,71 \pm$ & $327,41 \pm$ & $2744,67 \pm$ \\
& 24,85 & 7,01 & 166,64 & 148,91 & 83,27 & 92,36 & 535,27 \\
\hline
\end{tabular}

Fonte: Calculados a partir de teores levantados em arquivos da Sabesp

Obs.: Linha hachurada: Valores médios dos teores calculados para os resíduos frescos dispostos no corpo Norte

Tabela 5 - Valores de pH medidos no resíduo disposto do

Corpo Norte

Table 5 - Values of $\mathrm{pH}$ measured in the residues of the North Body

\begin{tabular}{|c|c|c|c|}
\hline AMOSTRA & $\begin{array}{c}\text { INTERVALO } \\
\text { AMOSTRADO (m) }\end{array}$ & $\begin{array}{l}\text { PONTO MEDIO } \\
\text { (m) }\end{array}$ & $\mathrm{pH}$ \\
\hline CNA-01 & $0,10 a 0,20$ & 0.15 & 7,45 \\
\hline $\mathrm{CNA}-02$ & 0,20 a 0,40 & 0,30 & 7,33 \\
\hline CNA- 03 & $0,40 \mathrm{a} 0,60$ & 0,50 & 7,35 \\
\hline CNA-04 & 0,80 a 1,00 & 0,90 & 7,67 \\
\hline CNA-05 & 1,80 a 2,00 & 1,90 & 7,46 \\
\hline CNA-06 & $2,70,2,80$ & 2,75 & 7,77 \\
\hline Média & \multicolumn{3}{|c|}{7,51} \\
\hline Desvio Padrăo & \multicolumn{3}{|c|}{0,18} \\
\hline Erro da média & \multicolumn{3}{|c|}{0.07} \\
\hline
\end{tabular}

Comparação entre os teores medidos no resíduo disposto e calculados para os resíduos frescos Para avaliar o comportamento dos metais após a exposição dos resíduos frescos ao ar livre, foram comparados os teores $T_{f}$ dos resíduos frescos com os teores $\mathrm{T}_{\mathrm{d}}$ dos resíduos dispostos. $\mathrm{A}$ partir dessa comparação determinou-se o valor da "Parcela Removida" de cada metal. Isso foi feito por meio do cálculo da diferença $(\Delta T \pm t)$ entre os teores $(T f \pm t)$, calculados para cada metal nos resíduos frescos (Tabela 4) e os respectivos teores $\left(\mathrm{T}_{\mathrm{d}}\right)$, medidos nos resíduos dispostos em cada profundidade (Tabela 6).

Os teores $T_{f}$ dos resíduos frescos foram considerados como "valores médios mais ou menos um erro da média corrigido pelo fator " $t$ " de Student". Já os teores $T_{d}$ do resíduo disposto foram considerados como os "valores efetivamente medidos pela análise química executada com abertura por ácidos fortes a quente". A Parcela Removida foi calculada pela expressão
$(\Delta \mathrm{T} \pm \mathrm{t})=[(\mathrm{Tf} \pm \mathrm{t})-\mathrm{Td}]$. Os resultados são apresentados na Tabela 7.

Valores positivos de $((\Delta \mathrm{T} \pm \mathrm{t})$ representam valores efetivamente possíveis para a Parcela Removida de cada metal. Essa parcela existe para todos os metais apenas nas amostras do topo do pacote. fontes:

Já os valores negativos obtidos para $(\Delta \mathrm{T} \pm \mathrm{t})$ podem ter duas

. Valores de $\Delta \mathrm{T}<0$ : indicam teores no resíduo disposto superiores aos teores do resíduo fresco. Essa incongruência ocorre em amostras da base do pacote de resíduos para os metais $\mathrm{Cr}$ e $\mathrm{Cu}$ e de forma mais generalizada para o $\mathrm{Zn}$. Existem duas explicações para este fato:

- Subestimação dos teores médios calculados para os metais nos resíduos frescos. Explicação plausível para $\mathrm{Cr}, \mathrm{Cu}$ $\mathrm{eZn}$.

- Enriquecimento de metais na base do pacote de resíduos em função de uma eventual remobilização do topo para a base. Explicação plausível para $\mathrm{Cr}$ e $\mathrm{Cu}$.

Valores dos fatores " $t$ " de Student muito elevados: ocorrem em função de desvios padrão também elevados, calculados para o conjunto dos teores originais que serviram para o cálculo dos teores médios do resíduo fresco.

Para que o comportamento da Parcela Removida de cada metal ficasse mais evidente, calculou-se a relação percentual entre o termo médio $\Delta \mathrm{T}$ da Parcela Removida de cada metal (Tabela 7) e o respectivo termo médio do teor $\mathrm{T}_{\mathrm{f}}$ no resíduo fresco original (Tabela 5), ambos sem considerar o fator $t$. Esse valor percentual foi denominado "Taxa de Remoção Relativa" e foi calculado para cada metal através da expressão $R_{R}(\%)=$ $[(\Delta \mathrm{T} / \mathrm{Tf}) .100]$. Os resultados obtidos são apresentados na Tabela 8.

Os valores da Taxa de Remoção Relativa levam às seguintes observações:

- Ocorreu a diminuição nos teores de praticamente todos os metais contidos nos resíduos frescos após a sua disposição 


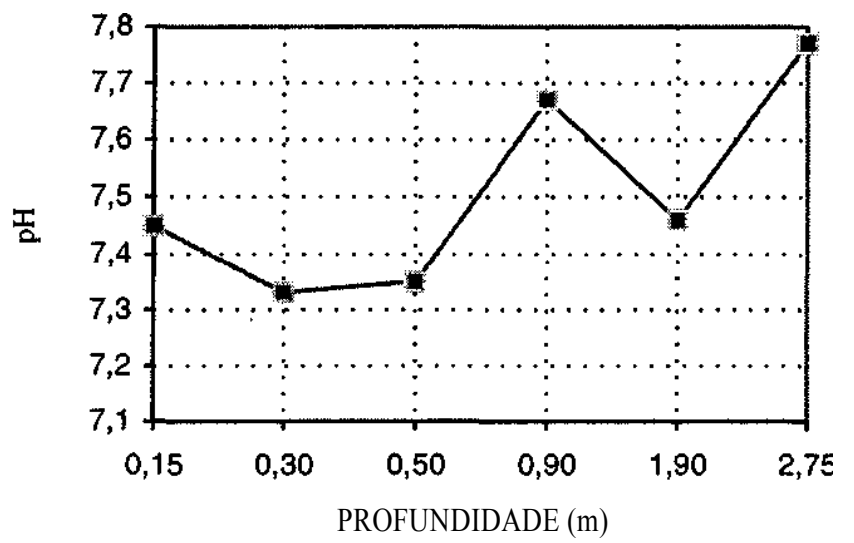

Figura l - Variação do pH de acordo com a-profundidade do resíduo disposto no Corpo Norte

Figure 1 - Variation of $\mathrm{pH}$ according to depth of the residue disposed in the North Body

no campo, principalmente no terço superior do pacote, até a profundidade de $1,00 \mathrm{~m}$.
- Não ocorreu diminuição dos teores de $\mathrm{Cr}$ e $\mathrm{Cu}$ abaixo de $1,00 \mathrm{~m}$ de profundidade.

- Praticamente não houve remoção de $\mathrm{Zn}$, exceto na camada mais superficial do pacote e em uma única amostra das zonas internas dos resíduos.

Esses comportamentos, conforme já foi mencionado, podem estar relacionados a uma possível subestimação dos teores médios calculados para $\mathrm{Cr}, \mathrm{Cu}$ e $\mathrm{Zn}$ nos resíduos frescos ou a uma remobilização de $\mathrm{Cr}$ e $\mathrm{Cu}$ em direção à base do pacote de resíduos.

Comparação entre si dos comportamentos dos metais no resíduo disposto Para poder comparar os comportamentos dos diversos metais entre si, em termos da sua remoção do resíduo disposto, utilizou-se os valores das Taxas de Remoção Relativa. No entanto, para que a comparação fosse feita com maior rigor, foram recalculados os valores, convencionandose como $100 \%$ os valores mais elevados de $R_{R}$ para cada metal. Obteve-se assim os valores da "Taxa de Remoção Relativa Recalculada" ( $\left.\mathrm{R}_{\mathrm{R}}^{\prime}\right)$ apresentados na Tabela 9. A partir dos valores obtidos para $R_{R}^{\prime}$ foram identificados quatro comportamentos distintos:

Tabela 6 - Teores medidos para os metais no resíduo disposto $\left(T_{d}\right)$ - Abertura: ácidos fortes a quente

Table 6 - Mean content of metais measured in the waste disposal $\left(\mathrm{T}_{\mathrm{d}}\right)$. Attack by strong hot acids.

\begin{tabular}{|c|c|c|c|c|c|c|c|c|c|c|c|}
\hline \multirow[t]{2}{*}{ Amostra } & \multirow{2}{*}{$\begin{array}{l}\text { INTERVALO } \\
\text { (m) }\end{array}$} & \multirow{2}{*}{$\begin{array}{l}\text { PONTO } \\
\text { MEDIO } \\
\text { (m) }\end{array}$} & \multicolumn{9}{|c|}{ TEOR T $_{d}$ NO RESÍDUO DISPOSTO (mg/kg) - Base seca } \\
\hline & & & $\mathrm{Ag}$ & $\mathrm{Cd}$ & $\mathrm{Cr}$ & $\mathrm{Cu}$ & $\mathrm{Ni}$ & $\mathrm{Pb}$ & $\mathrm{Zn}$ & $\mathrm{Fe}$ & Mn \\
\hline CNA-01 & 0,10 a 0,20 & 0,15 & 12,70 & 5,00 & 257,00 & 410,00 & 208,00 & 103,00 & 950,00 & 43900,00 & 490,00 \\
\hline CNA-02 & 0,20 a 0,40 & 0,30 & 21,20 & 9,00 & 470,00 & 610,00 & 274,00 & 143,00 & 1570,00 & 40900,00 & 510,00 \\
\hline CNA-03 & 0,40 a 0,60 & 0,50 & 21,00 & 8,20 & 730,00 & 520,00 & 320,00 & 163,00 & 1490,00 & 47000,00 & 620,00 \\
\hline CNA-04 & 0,80 a 1,00 & 0,90 & 21,40 & 7,70 & 640,00 & 510,00 & 280,00 & 147,00 & 1400,00 & 39500,00 & 550,00 \\
\hline CNA-05 & 1,80 a 2,00 & 1,90 & 36,20 & 14,40 & 870,00 & 820,00 & 400,00 & 224,00 & 1710,00 & 41900,00 & 350,00 \\
\hline CNA-06 & 2,70 a 2,80 & 2,75 & 35,00 & 9.80 & 910,00 & 770,00 & 395,00 & 220,00 & 2750,00 & 38700,00 & 380,00 \\
\hline \multicolumn{3}{|c|}{ Média } & 24,58 & 9,02 & 647,17 & 606,67 & 312,83 & 166,67 & 1645,00 & 41983,33 & 483,33 \\
\hline \multicolumn{3}{|c|}{ Desvio Padrāo } & 9,16 & 3,10 & 248,70 & 159,83 & 74,80 & 47,21 & 599,66 & 3064,91 & 102,31 \\
\hline \multicolumn{3}{|c|}{ Erro da média } & 3,74 & 1,27 & 101,54 & 65,25 & 30,54 & 19,28 & 244,82 & 1251,29 & 41,77 \\
\hline \multicolumn{3}{|c|}{$\begin{array}{l}\text { Valor mais provável (limite de } \\
\text { confiança de } 90 \% \text { ) (Student) }\end{array}$} & $\begin{array}{c}24,58 \pm \\
7,54\end{array}$ & $\begin{array}{c}9,02 \pm \\
2,56\end{array}$ & $\begin{array}{c}647,17 \pm \\
204,60\end{array}$ & $\begin{array}{c}606,67 \pm \\
131,48\end{array}$ & $\begin{array}{c}312,83 \pm \\
61,54\end{array}$ & $\begin{array}{c}166,67 \pm \\
38,85\end{array}$ & $\begin{array}{r}1645,00 \\
\pm 493,31 \\
\end{array}$ & $\begin{array}{l}41983,33 \pm \\
2521,34\end{array}$ & $\begin{array}{l}483,33 \\
\pm 84,17\end{array}$ \\
\hline
\end{tabular}

Tabela 7 - Parcela Removida ( $T \pm t$ ) de cada metal em cada profundidade Table 7 - Removed Parcel ( $\mathrm{T} \pm \mathrm{t}$ ) of each metal by depth

\begin{tabular}{|c|c|c|c|c|c|c|c|c|c|}
\hline \multirow[t]{2}{*}{ Amostra } & \multirow{2}{*}{$\begin{array}{l}\text { Intervalo } \\
\text { amostrado } \\
\text { (m) }\end{array}$} & \multirow{2}{*}{$\begin{array}{l}\text { Ponto } \\
\text { médio } \\
\text { (m) }\end{array}$} & \multicolumn{7}{|c|}{$\begin{array}{l}\text { PARCELA REMOVIDA }(\Delta \mathrm{T} \pm \mathrm{t})(\mathrm{mg} / \mathrm{kg}) \\
\qquad(\Delta \mathrm{T} \pm \mathrm{t})=\left[\left(\mathrm{T}_{\mathrm{f}} \pm \mathrm{t}\right)-\mathrm{T}_{\mathrm{d}}\right]\end{array}$} \\
\hline & & & $\mathrm{Ag}$ & $\mathrm{Cd}$ & $\mathrm{Cr}$ & $\mathrm{Cu}$ & $\mathrm{Ni}$ & $\mathrm{Pb}$ & $\mathrm{Zn}$ \\
\hline CNA-01 & 0,10 a 0,20 & 0,15 & $37,30 \pm 16,11$ & $20,67 \pm 13,19$ & $548,45 \pm 195,44$ & $328,82 \pm 216,77$ & $270,00 \pm 111,04$ & $199,44 \pm 103,08$ & $542,90 \pm 282,29$ \\
\hline CNA-02 & 0,20 a 0,40 & 0,30 & $28,80 \pm 16,11$ & $16,67 \pm 13,19$ & $335,45 \pm 195,44$ & $12882+2167$ & $204,00 \pm 111,04$ & $159,44 \pm 103,08$ & 925101928229 \\
\hline $\mathrm{CNA}-03$ & 0,40 a 0,60 & 0,50 & $29,00 \pm 16,11$ & $17,47 \pm 13,19$ & 7545419544 & $218,82 \pm 216,77$ & $158,00 \pm 111,04$ & $139,44 \pm 103,08$ & $15 \times 14=82,9$ \\
\hline CNA-04 & 0,80 a 1,00 & 0,90 & $28,60 \pm 16,11$ & $17,97 \pm 13,19$ & $165,45 \pm 105,4$ & $228,82 \pm 216,77$ & $198,00 \pm 111,04$ & $155,44 \pm 103,08$ & $74,90+282,29$ \\
\hline CNA-05 & 1,80 a 2,00 & 1,90 & $4860 \div 1611$ & $11,27 \pm 13,19$ & $6455+195,4$ & $8118+21677$ & $78,00+11004$ & $7844+10908$ & $235 \times 1 / 28020$ \\
\hline CNA-06 & 2,70 a 2,80 & 2,75 & $1509+16,1$ & $15,87 \pm 13,19$ & $10 \% 55+19544$ & $21,18+2167$ & $8300=\mathrm{JW}$ & $7 / 24+10308$ & $127310+28+2$ \\
\hline \multicolumn{3}{|c|}{$\Delta \mathrm{T}$ Médio $\pm \mathrm{t}$} & $25,42 \pm 16,11$ & $\mid 16,65 \pm 13,19$ & $18747+19544$ & 15088122172 & $165,17 \pm 111, .04$ & $135,77 \pm 103,06$ & $10297=28020$ \\
\hline
\end{tabular}

OBS: $\quad$ 1. Área hachurada: Amostras que podem resultar em $(\Delta \mathrm{T} \pm \mathrm{t})<\mathrm{O}$ indicando não ocorrência de remoção.

2, Nas amostras com $\Delta \mathrm{T}$ negativo, considerou-se que não houve remoção $(\Delta \mathrm{T}=0)$ para o cálculo do $\Delta \mathrm{T}$ Médio. 
1.Cd: Metal removido intensamente de todo o perfil de resíduos de forma quase homogénea.

2.Ag, Ni e Pb: Metais de remoção intensa até a profundidade de $1,00 \mathrm{~m}$ e mais discreta a partir daí.

\section{Cu e Cr: Metais removidos somente até $1,00 \mathrm{~m}$}

4. Zn: Metal com remoção pequena e localizada.

É importante ressaltar que $\mathrm{Cr}, \mathrm{Cu}$ e $\mathrm{Zn}$ mostram um comportamento diferenciado, apresentando Taxas de Remoção Relativa bem inferiores à dos demais metais, principalmente na base do pacote de resíduos. Tal comportamento não é o esperado para esses metais, usualmente mais solúveis que os demais em solos naturais.

Deve-se considerar entretanto, que os resíduos têm composição e origem muito diferentes das dos solos naturais. Não é prudente portanto, a realização de previsões ou comparações quanto ao comportamento dos metais contidos nos resíduos, tendo como com base os seus comportamentos geoquímicos em solos naturais.

Isto posto, pode-se tentar explicar o comportamento diferenciado do $\mathrm{Cr}, \mathrm{Cu}$ e $\mathrm{Zn}$ nos resíduos pela ocorrência, simultânea ou não, de dois fatores:

Erros na amostragem e/ou análise ocorridos no monitoramento executado pela Sabesp no resíduo fresco original, que podem ter levado a uma subestimação de teores, principalmente para $\mathrm{Zn}$, no resíduo fresco.
. Remobilização interna de metais no resíduo disposto, que poderia ter provocado o aumento dos seus teores na base do pacote, principalmente para $\mathrm{Cu}$ e $\mathrm{Cr}$.

\section{Caracterização do solo sotoposto aos resíduos}

DETERMINAÇAO DO $\mathrm{pH}$ No solo sotoposto aos resíduos foram coletadas 15 amostras num perfil vertical, sendo 7 amostras de canal e 8 amostras de trado. Essas amostras apresentaram os valores de $\mathrm{pH}$ mostrados na Tabela 10, na qual se observa valores médios de $\mathrm{pH}$ situados entre $5,57 \mathrm{e}$ 6,09, caracterizando condições ligeiramente ácidas.

A variação vertical dos pH's do solo sotoposto aos resíduos pode ser observada na Figura 2. Nela verifica-se que, excluindo-se a amostra de solo mais próxima aos resíduos, que possui $\mathrm{pH}$ igual a 6,28, ocorrem duas zonas com comportamentos distintos:

A primeira vai da profundidade $3,10 \mathrm{~m}$ (logo abaixo do contato solo-resíduo) até a profundidade $5,10 \mathrm{~m}$. Nessa zona ocorre um aumento constante no valor do $\mathrm{pH}$ de 4,79 para 6,48 .

A segunda vai da profundidade de $5,10 \mathrm{~m}$ até o final do perfil a $6,10 \mathrm{~m}$. Nessa zona ocorre uma leve tendência de decréscimo do $\mathrm{pH}$, de valores próximos a 6,35 para valores próximos a 6,12 , com exceção da amostra mais profunda que tem $\mathrm{pH}$ de 6,45 .

Verificou-se também que os pH's do solo sotoposto são inferiores aos $\mathrm{pH}$ 's dos resíduos dispostos. Este fato sugere

Tabela 8 - Taxa de Remoção Relativa (RR): Relação percentual entre o termo médio da Parcela Removida_Te o Teor médio calculado para o resíduo fresco $\left(T_{t}\right)$ para cada metal em cada profundidade

Table 8 - Percent Relative Remotion Rate $(\mathrm{RR})=$ mid term of the Removed Parcel $T$ devidee by the calculated average content of the fresh residue of each metal at several depths

\begin{tabular}{|c|c|c|c|c|c|c|c|c|c|}
\hline \multirow[t]{2}{*}{ Amostra } & \multirow{2}{*}{$\begin{array}{l}\text { Intervalo } \\
\text { amostrado } \\
\text { (m) }\end{array}$} & \multirow{2}{*}{$\begin{array}{l}\text { Ponto } \\
\text { médio } \\
\text { (m) }\end{array}$} & \multicolumn{7}{|c|}{$\begin{array}{c}\text { TAXA DE REMOÇÃO RELATIVA }\left(\mathrm{R}_{\mathrm{R}}\right) \\
\mathrm{R}_{\mathrm{R}}(\%)=\left[\left(\Delta \mathrm{T} / \mathrm{T}_{\mathrm{r}}\right) \cdot 100\right]\end{array}$} \\
\hline & & & $\mathrm{Ag}$ & $\mathrm{Cd}$ & $\mathrm{Cr}$ & $\mathrm{Cu}$ & $\mathbf{N i}$ & $\mathrm{Pb}$ & $\mathrm{Zn}$ \\
\hline CNA-01 & 0,10 a 0,20 & 0,15 & 74,60 & 80,52 & 68,09 & 44,51 & 56,49 & 65,94 & 36,81 \\
\hline CNA-02 & 0,20 a 0,40 & 0,30 & 57,60 & 64,94 & 41,65 & 17,43 & 42,68 & 52,71 & 0,00 \\
\hline CNA-03 & 0,40 a 0,60 & 0,50 & 58,00 & 68,05 & 9,37 & 29,62 & 33,05 & 46,11 & 0,00 \\
\hline CNA-04 & 0,80 a 1,00 & 0,90 & 57,20 & 70,00 & 20,54 & 30,97 & 41,42 & 51,40 & 5,08 \\
\hline CNA-05 & 1,80 a 2,00 & 1,90 & 27,60 & 43,90 & 0,00 & 0,00 & 16,31 & 25,94 & 0,00 \\
\hline CNA-06 & 2,70 a 2,80 & 2,75 & 30,00 & 61,82 & 0,00 & 0,00 & 17,36 & 27,25 & 0,00 \\
\hline \multicolumn{3}{|c|}{$\mathrm{R}_{\mathrm{R}}$ Médio } & 50,83 & 64,87 & 23,28 & 20,42 & 34,55 & 44,89 & 6,98 \\
\hline
\end{tabular}

Obs.: Valor $\mathrm{R}_{\mathrm{R}}=0,00$ : Não ocorreu redução do teor em relação ao teor original do resíduo fresco

Tabela 9 - Taxa de Remoção Relativa Recalculada $\left(R^{\prime} R\right)$ adotando o valor máximo como 100\%

Table 9 - Recalculated Relative Remotion Rate (R'R) adopting $100 \%$ as maximum value

\begin{tabular}{|c|c|c|c|c|c|c|c|c|c|}
\hline \multirow[t]{2}{*}{ Amostra } & \multirow{2}{*}{$\begin{array}{l}\text { Intervalo } \\
\text { amostrado } \\
\text { (m) }\end{array}$} & \multirow{2}{*}{$\begin{array}{l}\text { Ponto } \\
\text { médio } \\
(\mathrm{m})\end{array}$} & \multicolumn{7}{|c|}{ TAXA DE REMOÇÃO RELATIVA RECALCULADA (R' ${ }^{\prime}$ ) } \\
\hline & & & $\mathrm{Ag}$ & $\mathrm{Cd}$ & $\mathrm{Cr}$ & $\mathrm{Cu}$ & $\mathrm{Ni}$ & $\mathrm{Pb}$ & $\mathrm{Zn}$ \\
\hline CNA-01 & 0,10 a 0,20 & 0,15 & 100,00 & 100,00 & 100,00 & 100,00 & 100,00 & 100,00 & 100,00 \\
\hline CNA-02 & 0,20 a 0,40 & 0,30 & 77,21 & 80,65 & 61,16 & 39,15 & 75,55 & 79,93 & 0,00 \\
\hline CNA-03 & 0,40 a 0,60 & 0,50 & 77,74 & 84,51 & 13,89 & 66,54 & 58,50 & 70,00 & 0,00 \\
\hline CNA-04 & 0,80 a 1,00 & 0,90 & 76,67 & 86,93 & 30,16 & 69,57 & 73,34 & 77,94 & 13,80 \\
\hline CNA-05 & 1,80 a 2,00 & 1,90 & 36,99 & 54,52 & 0,00 & 0,00 & 28,87 & 39,34 & 0,00 \\
\hline CNA-06 & 2,70 a 2,80 & 2,75 & 40,21 & 76,77 & 0,00 & 0,00 & 30,73 & 41,32 & 0,00 \\
\hline \multicolumn{3}{|c|}{$R_{R}^{\prime} \quad$ Médio } & 68,13 & 80,56 & 34,20 & 45,88 & 61,16 & 67,99 & 18,96 \\
\hline
\end{tabular}


que os metais que tenham eventualmente chegado até o solo, carregados em solução nos fluidos originários dos resíduos, têm grande probabilidade de ter permanecido em solução nesses mesmos fluidos.

DETERMINAÇÃO DOS METAIS PESADOS A análise química dos metais pesados contidos no solo sotoposto chegou aos resultados mostrados na Tabela 11.

Não foi possível a avaliação geoquímica e ambiental desses resultados por meio da sua comparação com teores de solos não contaminados do próprio local pois, infelizmente, esses dados não estão disponíveis. Assim, optou-se pela comparação com teores médios de metais em rochas similares às existente no local (sedimentos fluviais areno-argilosos), extraídos de Alloway (1990) e exibidos na Tabela 12. Considerando-se que o solo sotoposto aos resíduos é constituído por sedimentos siltico-arenosos, com um pequeno teor de arguas, utilizou-se para comparação os teores médios adotados por Alloway (1990) para arenitos e arguas, assumindo por precaução sempre o maior valor.

Esse procedimento conduziu às seguintes observações:

Utilizando como padrão os teores médios naturais de rochas similares (Alloway 1990), conclui-se que não ocorrem anomalias significativas de $\mathrm{Cd}, \mathrm{Cr}, \mathrm{Fe}, \mathrm{Ni}, \mathrm{Mn}$ e $\mathrm{Zn}$ nos solos sotopostos aos resíduos. Pode-se afirmar portanto, que os solos não retiveram quantidades anômalas desses metais. No entanto, pode-se afirmar também que os solos retiveram pequenas quantidades de $\mathrm{Cr}$, Fe, Ni e $\mathrm{Mn}$. Essa pequena retenção fica evidente ao se observar a variação dos teores desses metais com a profundidade. A Tabela 11 mostra teores mais elevados de $\mathrm{Cr}$, Fe, Ni e Mn numa faixa mais superficial do solo, que vai do contato com os resíduos (nível 2,80m) até a profundidade de 1,30m (nível 4,10m). A partir daí os teores desses 4 metais diminuem significativamente.

Os teores de $\mathrm{Ag}$ são anômalos em dois níveis:

1. No nível situado imediatamente abaixo do contato com os resíduos (espessura de $0,20 \mathrm{~m}$ ),

2. No nível situado entre $4,70 \mathrm{~m}$ e $5,30 \mathrm{~m}$ (espessura de $0,60 \mathrm{~m}$ ), assumindo valores até 12 vezes o teor normal, como é o caso da faixa situada entre $4,70 \mathrm{~m}$ e $4,90 \mathrm{~m}$.

Nos demais intervalos os teores de Ag são de 1 a 2 vezes o teor normal. Portanto, existem teores anômalos de $\mathrm{Ag}$ em praticamente todo o perfil.

$\mathrm{O} \mathrm{Cu}$ também apresenta teores até 2 vezes o teor normal, com exceção dos intervalos situados entre $2,80 \mathrm{~m}$ e $3,00 \mathrm{~m}$ (espessura de $0,20 \mathrm{~m}$ logo abaixo do contato com os resíduos) e 4,50m a 4,90m (espessura de 0,40m), onde ocorre em teores considerados normais. $\mathrm{O}$ teor de $\mathrm{Cu}$ é especialmente elevado no intervalo situado entre $5,90 \mathrm{~m}$ e $6,10 \mathrm{~m}$, onde atinge um valor quase 6 vezes o valor normal. Portanto, ocorrem teores anômalos de $\mathrm{Cu}$ em níveis localizados do perfil.

$\mathrm{O} \mathrm{Pb}$ apresenta valores anômalos de até 2 vezes o teor normal, num intervalo com espessura de $1,20 \mathrm{~m}$, situado logo abaixo do contato com os resíduos, de 2,80m até 4,00m. Abaixo deste intervalo, o perfil apresenta teores considerados normais de $\mathrm{Pb}$. Portanto, existem teores anômalos de $\mathrm{Pb}$ apenas nos níveis mais superficiais do solo.

Portanto, observou-se que houve retenção de quantidades anómalas apenas dos metais $\mathrm{Ag}, \mathrm{Cu}$ e $\mathrm{Pb}$ em profundidades variáveis do solo sotoposto aos resíduos.

Já os metais $\mathrm{Cr}$, Fe, Ni e Mn foram retidos em quantidades muito pequenas, apenas na camada mais superficial do solo, com 1,30m de espessura, logo abaixo do contato com os resíduos. Não houve retenção de quantidades significativas de $\mathrm{Zn}$ e não houve nenhuma retenção de $\mathrm{Cd}$.

CONCLUSÕES Os resultados proporcionados pelo conjunto de análises realizadas nas amostras de resíduo possibilitam afirmar com segurança que os resíduos gerados e dispos-
Tabela 10 - Valores de pH's medidos no solo sotoposto aos resíduos do Corpo Norte

Table $1 \mathrm{O}-\mathrm{pH}$ values measured in the soil underneath the residues of North Body

\begin{tabular}{|c|c|c|c|}
\hline AMOSTRA & $\begin{array}{c}\text { INTERVALO } \\
\text { AMOSTRADO }(\mathrm{m})\end{array}$ & $\begin{array}{l}\text { PONTO MEDIO } \\
\text { (m) }\end{array}$ & $\mathrm{pH}$ \\
\hline CNA-07 & 2,80 a 3,00 & 2,90 & 6,28 \\
\hline CNA- 08 & 3,10 a 3,20 & 3,15 & 4,79 \\
\hline CNA -09 & 3,40 a 3,50 & 3,45 & 5,11 \\
\hline CNA-10 & 3,60 a 3,80 & 3,70 & 5,11 \\
\hline CNA-11 & 3,90 a 4,00 & 3.95 & 5,31 \\
\hline CNA.1 2 & 4.00 a 4,10 & 4,05 & 5,74 \\
\hline CNA-13 & 4,40 a 4,50 & 4,45 & 5,35 \\
\hline TNA-0] & 4,50 a 4,70 & 4,60 & 5,82 \\
\hline TNA-02 & 4,70 a 4,90 & 4,80 & 6,10 \\
\hline TNA-03 & 4,90 a 5,10 & 5,00 & 6,48 \\
\hline TNA-04 & 5,10 a 5,30 & 5,20 & 6,34 \\
\hline TNA 05 & 5,30 a 5,50 & 5,40 & 6.39 \\
\hline TNA-06 & 5,50 a 5,70 & 5,60 & 6,11 \\
\hline TNA-07 & 5,70 a 5,90 & 5,80 & 6.12 \\
\hline TNA-08 & 5,90 a 6,10 & 6,00 & 6,45 \\
\hline Média & \multicolumn{3}{|c|}{5.83} \\
\hline Desvio Padrăo & \multicolumn{3}{|c|}{0.56} \\
\hline Erro da média & \multicolumn{3}{|c|}{0.15} \\
\hline \multicolumn{4}{|c|}{ Vator mais provável (limite de confiança de $90 \%$ ) } \\
\hline
\end{tabular}

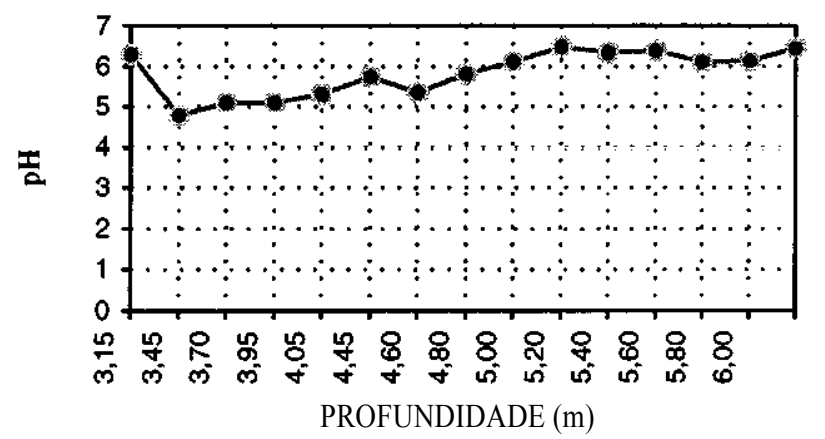

Figura 2 - Variação do pH de acordo com a profundidade do solo sotoposto ao Corpo Norte

Figure 2 - $\mathrm{pH}$ variation with depth in the soil underneath North Body

tos em Barueri estão sofrendo um processo de adaptação geoquímica às condições ambientais tropicais naturais. Este processo está ligado primeiramente a uma forte diminuição no valor do $\mathrm{pH}$ dos resíduos.

Os resíduos frescos no momento da sua geração, apresentavam pH's superiores a 11 , portanto francamente alcalinos. Decorridos 15 meses de exposição ao ar livre os valores de pH's diminuíram para 7,5. Essa queda no valor do $\mathrm{pH}$ dos resíduos deve ter sido consequência da sua disposição ao ar livre.

Corroborando essa conclusão, verifica-se uma discreta tendência de aumento no valor do $\mathrm{pH}$ do resíduo disposto, do topo (valores próximos a 7,3) para a base do pacote (valores próximos a 7,8). Assim, os valores de $\mathrm{pH}$ da zona mais próxima ao meio externo (topo) são ligeiramente inferiores aos da zona mais interna e profunda (base). Esse fato sugere que o agente causador da redução do $\mathrm{pH}$ tem origem no meio externo, podendo estar ligado às condições climático-ambientais. Portanto, a exposição dos resíduos frescos às condições tropicais pode ter sido um fator determinante na redução do valor do seu $\mathrm{pH}$, fato que contribuiria para a solubilização, mesmo que parcial, de compostos portadores de metais pesados. 
Tabela 11 - Teores dos metais no solo sotoposto - Abertura: ácidos fortes a quente Table 11 - Metal contents in the soil underneath North Body. Attack by strong and hot acids

\begin{tabular}{|c|c|c|c|c|c|c|c|c|c|c|c|}
\hline \multirow[t]{2}{*}{ AMOSTRA } & \multirow{2}{*}{$\begin{array}{l}\text { INTERVALO } \\
\text { (m) }\end{array}$} & \multirow{2}{*}{$\begin{array}{l}\text { PONTO } \\
\text { MEDIO } \\
\text { (m) }\end{array}$} & \multicolumn{9}{|c|}{ TEOR T $_{s}$ NO SOLO $(\mathrm{mg} / \mathrm{kg})$ - Base seca } \\
\hline & & & Ag & $\mathrm{Cd}$ & $\mathrm{Cr}$ & $\mathrm{Cu}$ & $\mathrm{Ni}$ & $\mathrm{Pb}$ & Zn & $\mathrm{Fe}$ & Mn \\
\hline CNA-07 & $2,80 a 3,00$ & 2,90 & 609 & nd & 33,00 & 36,00 & 27,00 & 2700 & 35,00 & 18400,00 & 30,00 \\
\hline CNA-08 & 3,10 a 3,20 & 3,15 & 0,40 & nd & 32,00 & 47.00 & 13,00 & 25,00 & 38,00 & 17500,00 & 20,00 \\
\hline CNA-09 & 3,40 a 3,50 & 3,45 & 0,30 & nd & 32,00 & 48,00 & 13,00 & 30,00 & 30,00 & 19500,00 & 20,00 \\
\hline CNA-10 & 3,60 a 3,80 & 3,70 & 030 & nd & 37,00 & 13,00 & 16,00 & 3500 & 44,00 & 22400,00 & 40,00 \\
\hline CNA-11 & 3,90 a 4,00 & 3,95 & 0,20 & nd & 30,00 & 6200 & 13,00 & 3700 & 38,00 & 19400,00 & 40,00 \\
\hline $\mathrm{CNA}-12$ & 4.00 a 4.10 & 4,05 & nd & nd & 24,00 & 52,0 & 11,00 & 21,00 & 36,00 & 11100,00 & 10,00 \\
\hline $\mathrm{CNA}-13$ & 4,40 a 4,50 & 4,45 & 0,10 & nd & 14,00 & 43,00 & 7,00 & 20,00 & 30,00 & 5500,00 & 10,00 \\
\hline TNA-01 & 4,50 a 4,70 & 4,60 & 0,10 & nd & 11,00 & 32,00 & 6,00 & 19,00 & 32,00 & 4900,00 & 10,00 \\
\hline TNA-02 & 4,70 a 4,90 & 4,80 & 506 & nd & 18,00 & 38,00 & 9,00 & 21,00 & 40,00 & 9600,00 & 20,00 \\
\hline TNA-03 & 4,90 a 5,10 & 5,00 & 102 & nd & 10,00 & $82 ; 00$ & 6,00 & 16,00 & 40,00 & 5000,00 & 20,00 \\
\hline TNA-04 & 5,10 a 5,30 & 5,20 & 6 60 & nd & 18,00 & 6000 & 4,00 & 18,00 & 30,00 & 5300,00 & 10,00 \\
\hline TNA-05 & 5,30 a 5,50 & 5,40 & 0,30 & nd & 6,00 & 60,90 & 4,00 & 16,00 & 27,00 & 2500,00 & 10.00 \\
\hline TNA-06 & 5,50 a 5,70 & 5,60 & 0,40 & nd & 10,00 & 4300 & 7,00 & 14,00 & 33,00 & 3000,00 & 10,00 \\
\hline TNA-07 & 5,70 a 5,90 & 5,80 & 0,40 & nd & 6,00 & 91,00 & 5,00 & 11,00 & 36,00 & 3200,00 & 20.00 \\
\hline TNA-08 & 5,90 a 6,10 & 6,00 & 030 & nd & 4,00 & 6901 & 8.00 & 13,00 & 43,00 & 5600,00 & 50,00 \\
\hline \multicolumn{3}{|c|}{ Média } & 0,60 & nd & 19,00 & 66,20 & 9.93 & 21,53 & 35,47 & 10193,33 & 21,33 \\
\hline \multicolumn{3}{|c|}{ Erro da média } & 0,20 & nd & 2,94 & 12,23 & 1,55 & 2,02 & 1,32 & 1857,02 & 3,36 \\
\hline \multicolumn{3}{|c|}{$\begin{array}{c}\text { Valor mais provável } \\
\text { ( Limite de confiança de } 90 \% \text { ) }\end{array}$} & $\begin{array}{c}0,60 \pm \\
0,35\end{array}$ & nd & $\begin{array}{c}19,00 \pm \\
5,17\end{array}$ & $\begin{array}{c}66,20 \pm \\
21,52\end{array}$ & $\begin{array}{c}9,93 \pm \\
2,73\end{array}$ & $\begin{array}{l}21,53 \\
\pm 3,55\end{array}$ & $\begin{array}{c}35,47 \pm \\
2,32\end{array}$ & $\begin{array}{c}10193,33 \pm \\
3268,35\end{array}$ & $\begin{array}{c}21,33 \pm \\
5,91\end{array}$ \\
\hline
\end{tabular}

Hachurado menos denso: Valores anômalos até 2 vezes o teor normal mostrado na Tabela 12.

Hachurado mais denso: Valores anômalos superiores a 2 vezes o teor normal mostrado na Tabela 12.

Tabela 12 - Abundância média natural de alguns metais pesados $(\mathrm{mg} / \mathrm{kg})$

Table 12 - natural mean abundance of some of the heavy metais $(\mathrm{mg} / \mathrm{kg})$

\begin{tabular}{|c|c|c|c|c|}
\hline METAL & CROSTA & $\begin{array}{c}\text { ROCHAS } \\
\text { GRANITICAS }\end{array}$ & ARENITOS & ARGILAS \\
\hline $\mathrm{Ag}_{\mathrm{g}}$ & 0,07 & 0,04 & 0.25 & 0,07 \\
$\mathrm{Cd}$ & 0.1 & 0.09 & 0,05 & 0,22 \\
$\mathrm{Cr}$ & 100 & 4 & 35 & 90 \\
$\mathrm{Cu}$ & 50 & 13 & 30 & 39 \\
$\mathrm{Mn}$ & 950 & 400 & 460 & 850 \\
$\mathrm{Ni}$ & $\mathbf{8 0}$ & 0.5 & 9 & 68 \\
$\mathrm{~Pb}$ & 14 & 24 & 10 & 23 \\
$\mathrm{Z}_{\mathrm{j}}$ & 75 & 52 & 30 & 120 \\
\hline
\end{tabular}

Fonte: Alloway (1990)

A comparação direta entre os teores de metais nas amostras de resíduos dispostos e os teores médios originais dos mesmos metais nos resíduos frescos demonstra que ocorreu uma considerável diminuição nos teores de todos os metais durante os 15 meses de exposição dos resíduos ao ar livre. Com base na Taxa de Remoção Relativa pode-se afirmar que, em média, houve remoção de $64,87 \%$ de $\mathrm{Cd}, 50,83 \%$ de $\mathrm{Ag}, 44,89 \%$ de $\mathrm{Pb}, 34,55 \%$ do $\mathrm{Ni}, 23,28 \%$ de $\mathrm{Cr}, 20,42 \%$ de $\mathrm{Cu}$ e $6,98 \%$ de $\mathrm{Zn}$.

A ordem aparente para a intensidade relativa de remoção dos metais dos resíduos é: $\mathrm{Cd} \mathrm{Ag} \mathrm{Pb} \mathrm{Ni} \mathrm{Cr} \mathrm{Cu}>\mathrm{Zn}$. No entanto, essa ordem deve ser encarada com cautela, pois ela implica em comportamentos geoquímicos anômalos, principalmente para o $\mathrm{Zn}$ e em menor escala para $\mathrm{Cr}$ e $\mathrm{Cu}$. Esses metais apresentaram, em algumas profundidades do pacote de resíduos dispostos, teores superiores aos dos resíduos frescos. Uma explicação para esses comportamentos anômalos seria a subestimação dos teores médios dos metais, principalmente $\mathrm{Zn}$, nos resíduos frescos, em função de erros analíticos ou de amostragem. Outra explicação seria o enriquecimento nesses mestais nas porções inferiores do pacote de resíduos, provocada por uma remobilização interna do topo para a base do pacote, principalmente de $\mathrm{Cr}$ e $\mathrm{Cu}$.
As análises realizadas nas amostras do solo sotoposto ao pacote mostraram que ele sofreu influência direta dos resíduos. No entanto, essa influência é parcial e limitada. Verificou-se que o $\mathrm{pH}$ médio do solo é 5,83; valor inferior ao $\mathrm{pH}$ médio do resíduo disposto. Valores de $\mathrm{pH}$ com essa ordem de grandeza tendem a favorecer a permanência em solução dos metais que eventualmente tenham se solubilizado a partir dos resíduos e atingido o solo. Assim, o $\mathrm{pH}$ do solo indica condições físico-químicas desfavoráveis à fixação desses metais.

Os solos sotopostos aos resíduos não apresentam anomalias significativas para $\mathrm{Cd}, \mathrm{Cr}, \mathrm{Fe}, \mathrm{Ni}, \mathrm{Mn}$ e $\mathrm{Zn}$. Pode-se afirmar assim, que eles não retiveram quantidades anômalas da parcela desses metais que foi liberada dos resíduos. Mesmo assim, quando se observa os teores de $\mathrm{Cr}, \mathrm{Fe}, \mathrm{Ni}$ e $\mathrm{Mn}$ nas amostras de solo, nota-se uma discreta contaminação dos seus níveis mais superficiais. Essa contaminação é claramente detectável na faixa com cerca de $1,30 \mathrm{~m}$ de espessura (nível $2,80 \mathrm{~m}$ a nível $4,10 \mathrm{~m}$ ), logo abaixo do contato solo-resíduos. Observa-se que os teores de $\mathrm{Cr}, \mathrm{Fe}, \mathrm{Ni}$ e $\mathrm{Mn}$ nessa faixa são sistematicamente superiores aos teores medidos nos níveis mais profundos. Mesmo assim, eles se situam dentro dos limites considerados normais para solos similares.

Dessa forma, pode-se concluir também que os teores de $\mathrm{Cr}$, $\mathrm{Fe}, \mathrm{Ni}$ e Mn na faixa mais superficial do solo, antes da sua contaminação, eram inferiores aos teores considerados normais por Alloway (1990) para rochas similares.

Os únicos metais que foram detectados em teores claramente anômalos no solo são $\mathrm{Ag}, \mathrm{Cu}$ e $\mathrm{Pb}$. Os teores de $\mathrm{Ag}$ são mais elevados no nível situado imediatamente abaixo do contato com os resíduos e no nível situado entre 4,70m e $5,30 \mathrm{~m}$, onde assume teores até 12 vezes o teor normal. Nos demais níveis os teores de $\mathrm{Ag}$ são 1 a 2 vezes o teor normal.

O Cu também ocorre em teores superiores em até 2 vezes o teor normal, sendo especialmente elevado no nível situado entre $5,90 \mathrm{~m}$ e $6,10 \mathrm{~m}$, onde atinge um valor quase 6 vezes maior que o valor normal. 
$\mathrm{O} \mathrm{Pb}$ apresenta valores anômalos, até 2 vezes o teor limite, no nível situado abaixo do contato com os resíduos, que vai de 2,80m até $4,00 \mathrm{~m}$.

O metal $\mathrm{Zn}$ ocorre de forma homogênea no perfil de solo, e o Cd não foi detectado.

Como detectou-se contaminação por $\mathrm{Ag}$ e $\mathrm{Cu}$ em níveis profundos do solo sotoposto, conclui-se que este sofreu a percolação de fluidos contendo esses dois metais, pelo menos até as profundidades onde ocorreram as contaminações. É provável que esses fluidos também carregassem outros metais que, no entanto, não foram retidos pelo solo.

A conclusão mais abrangente deste trabalho é que decorridos 15 meses de exposição dos resíduos ao clima tropical natural, houve uma diminuição considerável do seu conteúdo inicial de metais pesados, certamente facilitada pela diminuição do seu $\mathrm{pH}$. Os metais removidos devem ter sido incorporados a soluções que migraram dos resíduos para o solo sotoposto. $\mathrm{O}$ solo reteve quantidades consideráveis apenas dos metais $\mathrm{Ag}, \mathrm{Cu}$ e $\mathrm{Pb}$. Ele reteve também pequenas quantidades de $\mathrm{Cr}$, Fe, $\mathrm{Mn}$ e Ni nos níveis mais superficiais e próximos aos resíduos. $\mathrm{O} \mathrm{Cd}$, metal extremamente tóxico, foi

\section{REFERÊNCIAS}

Alesii, B. A.; Fuller, W.H. ; Boyle, MV. 1980. Effect of leachate flow rate on metal migration through soil. Journal of Environmental Quality, 9:119-126.

Alloway, B. J. 1990. Heavy Metals in Soil, Alloway. B. J. (Ed), Blackie, Glasgow-London.

Andersson, A. 1977a. Heavy metais in swedish soils: on theirretention, distribution and amounts. Swedish Journal of Agricultural Researches, 7:7-20.

Andersson, A. 1977b. The distribution of heavy mtals in sils and soil material as influenced by the ionic fadius. Swedish Journal of Agricultural Researches, 7:79-83.

Andersson, A. (1979). On the distribution of heavy metais as compared to some other elements between grains size fractions in soils. Swedish Journal of Agricultural Researches, 9:7-13.

Anderson, A. \& Nilson, K.O. 1972. Enrichment of trace elements from sewage sludge fertilizers in soils and plants. Ambio, 1:176-179.

Argaman, Y. \& Weddle, C.L. 1973. Fate of heavy metais in physical-chemical treatment processes. Water 1973, American Institute of Chemical Engeenering Symposium Series, 70, 136, pp 400-414.

Assunção, J.C.B. 1996. Análise mineralógica, geoquímica e textural de Iodos gerados e dispostos pela ETE de Barueri, SP: Associações com Metais Pesados e seus Efeitos no Solo; São Paulo, 120p. (Dissertação-Mestrado) Instituto de Geociências, Universidade de São Paulo.

Bettiol, W. 1982. Utilização de lodo de esgoto como fertilizante. Colóquio Regional sobre Matéria Orgânica do Solo, Anais..., CENA/USP, Piracicaba, pp 227-232.

Bigham, F.T.; Page, A.L.; Mahler, RJ. \& Ganje, T.J. 1975. Growth and cadmiun accumulation on a soil treated with a cadmium-enriched sewage sludge. Journal of Environmental Quality, 4:207-211.

Calmano, W. 1988. Stabilization of dredged mud. In: Salomons W. \& Forstner U. (Eds.) Chemistry and Biology of Solid Waste - Dredged Material and Mining Tailings, Springer Verlag, pp 80.

Campanella, L. ; Cardarelli, E. ; Ferri, T. ; Petrônio, B.M. \& Pupella, A. 1985. Evaluation of toxic metais leaching from urban sludge. In: Pawlowski, L.; Alaerts G.; Lacy W. J. (Eds.) Chemistry for protection of the environment, Fifth International Conference, Proceedings, Leuven, Belgium, pp.3

Cotrim, A. R. 1991. Metais pesados na agricultura: consequências das elevadas concentrações de mercúrio, cádmio e chumbo nos solos. Relatório Interno, Produquímica Ind. e Com. Ltda.

Damasceno, S. 1996. Remoção de metais pesados em sistemas de tratamento de esgotos sanitários por processo de Iodos ativados e por um reatar compartimentado anaeróbio. São Carlos, 141p. (Dissertação-Mestrado) -Escola de Engenharia de São Carlos, Universidade de São Paulo.

Eckenfelder, J. 1991. Principies of Water Quality Management. Malabar-Krieger.

Etatec Consultores S/C Ltda. 1993. Relatório de caracterização dos Iodos gerados nas ETE's de Barueri e Suzano, Documento Interno - Sabesp.

Etep - Estudos Técnicos e Projetos Ltda. 1992. Disposição dos Iodos das cinco estações de tratamento de esgotos sanitários da região metropolitana de São Paulo -Solução Aterro Sanitário; São Paulo, Relatório Técnico PE 1144.

Forstner, U \& Wittmann, G. T. 1981. Metalpollution in the aquatic environment, Springer-Verlag, Berlin-Heüdelberg-New York.

Fuller, W. H. \& Warrick, A. W. 1985. Soils in waste treatment and utilization. Vols. 1 and 2, University of Arizona, USA, CRC Press, Florida.

Garrigan, G. A. 1977. Land applications guidelines for sludges contamined with toxic elements. Journal of Water Pollution Contrai Federation, 49:2380-2389. o mais intensamente removido dos resíduos, não sendo retido pelo solo. A maior parcela dos metais removidos dos resíduos deve ter permanecido em solução, sendo incorporada às águas superficiais e subterrâneas, tanto do local como do seu entorno, podendo inclusive, ter atingido a biota local.

Finalmente, é fundamental assinalar que os resíduos estudados são completamente diferentes de solos naturais, apresentando condições de $\mathrm{pH}$, umidade, teor de sólidos, teor de matéria orgânica e teor de cátions e ânions, maiores e menores, absolutamente singulares. As menções no texto quanto a "comportamentos geoquímicos contrários aos esperados" buscam, na realidade, ressaltar o fato de que resíduos são muito diferentes de solos naturais. Portanto, comparações de comportamentos geoquímicos de metais contidos nos resíduos com comportamentos dos mesmos metais em solos naturais é muito arriscada, praticamente inviável no atual momento. Ressalte-se que, um dos objetivos deste trabalho foi exatamente o de iniciar um processo de reconhecimento dos resíduos, de forma a que, no futuro, sejam estabelecidos padrões de comportamento dos metais, que sirvam, aí sim, como referência a outros estudos.

Gemert, W. J. T.; Quakernaat, J. \& Van Veen, H. J. 1988. Methods for treatment of contamined dredged sediments. In: Salomons W. \& Forstner U. (Eds.) Chemistry and Biology of Solid Waste - Dredged Material and Mining Tailings, Springer Verlag, pp 44-64.

John, M. K. \& Van Laerhoven, C. J. 1976. Effects of sewage sludge composition, aplication rate and lime regime on plant availbility of heavy metais. Journal of Environmental Quality, 5:246-250

Jorgensen, S. E. 1975. Do heavy metais prevent the agricultural use of municipal sludge?. Water Research, 9:163-170.

Jorgensen, S. E. \& Johnsen, I. 1989. Principies of Environmental Science and Technology, Elsevier, Amsterdam-Oxford-New York-Tokio.

Kelling, K. A.; Keeney, D. R.; Walsh, L. M. \& Ryan, J. A. 1977. A field study of the agricultural use of sewage sludge: III effect on uptake and sxtractability of sludge-born metais. Journal of Environmental Quality, 6:352-358.

Lake, D. L.; Kirk, P. W. W. \& Lester, J. N. 1984. Fractionation, characterization and spetiation of heavy metais in sewage sludge and sludge-amended soils: a review. Journal of Environmental Quality, 13:175-183.

Mattheus, P. J. 1982. Sewage sludge disposal and utilisations in the United Kingdom Water Service, London. 86(1037):324-326.

Negulescu, M. 1985. Municipal Waste Water Treatment; Developments In Water Science. Bucareste, Elsevier Ed., 596p.

Page, A. L. 1974. Fate and effects of trace elements in sewage sludge when applied to agricultural lands: a literature review study. Journal of Environment Protection Tech. Ser.; EPA-670/2-27-005. 96p.

Possa, M. V. \& Luz, A. B. 1984. Amostragem para processamento mineral. Série Tecnologia Mineral, $\mathrm{n}^{\circ} 30$.

Povinelli, J. 1987. Ação dos metais pesados nos processos biológicos de tratamento de águas residuárias. São Carlos, (Tese-Livre Docência), Escola de Engenharia de São Carlos da Universidade de São Paulo.

São Paulo (Estado) - SABESP - Cia. de Saneamento Básico do Estado de São Paulo, ETE- Barueri. 1994. Manual sobre o funcionamento da ETE de Barueri. 18p.

São Paulo (Estado) - SABESP - Cia. de Saneamento Básico do Estado de São Paulo, ETE- Barueri. 1994b. Monitoramento da água subterrânea. Documento Interno, $2 \mathrm{p}$.

Schalscha, E. B.; Morales, M.; Ahumada, I.; Schirado, T. \& Pratt, P. F. 1980. A fractionation of $\mathrm{Zn}, \mathrm{Cu}, \mathrm{Cr}$ and $\mathrm{Ni}$ in wastewater, solids and in soil. Agrochimica, 24:361-368

Schalscha, E. B.; Morales, M. ; Vergara, I. \& Chang, A. C. 1982. Chemical fractionation of heavy metais in wastewater-affected soils. Journal of Water Pollution Control Federation, 54:175-180.

Smith, S. R. 1994. Effect of soil $\mathrm{pH}$ on availability to crops of metais in sewage sludge-treated soils. I. Nickel, Copper and Zinc uptake and toxicity to ryegrass. Environmental Pollution, 85:321: 327.

Strett, J. J. ; Sabey, B. R. \& Lindsay, W. L. 1978. Influences of pH, cadmiun, sewage sludge and incubation time in the solubility and plant uptake of cadmium. Journal of Environmental Quality, 7:286-290.

Manuscrito A928

Recebido em 22 de julho de 1997

Revisã o dos autores em 30 de outubro de 1997 Revisão aceita em 5 de novembro de 1997 